\title{
Hidrocefalia congénita-neonatal: alternativas terapéuticas a la derivación. Una mirada a la terapia celular
}

\author{
Congenital-neonatal hydrocephalus: therapeutic alternatives to derivation. A look at cell \\ therapy
}

\author{
María J. Uparela-Reyes ${ }^{1}$, Alexis R. Narváez-Rojas², Loraine Quintana-Pájaro1, \\ Yancarlos Ramos-Villegas ${ }^{1}$ y Luis R. Moscote-Salazar ${ }^{1 *}$ \\ ${ }^{1}$ Departamento de Neurocirugía, Universidad de Cartagena, Cartagena de Indias, Colombia; ${ }^{2}$ Universidad Nacional Autónoma de Nicaragua, \\ Managua, Nicaragua
}

\begin{abstract}
Resumen
Introducción: La hidrocefalia de inicio fetal, perinatal y neonatal representa un gran reto terapéutico y a menudo cursa con un pronóstico neurológico pobre, debido a su etiología heterogénea, que incluye alteraciones del neurodesarrollo. Objetivo: Realizar una recopilación de los avances en terapia celular como propuesta que permite ampliar el espectro de tratamiento en la hidrocefalia congénita-neonatal. Desarrollo: Las intervenciones terapéuticas disponibles actualmente, como la derivación ventrículo-peritoneal y la tercera ventriculostomía, son insuficientes para resolver por completo la hidrocefalia y para prevenir o revertir los daños neurológicos asociados. Es por esto por lo que ha surgido la necesidad de crear nuevas alternativas terapéuticas a partir del conocimiento de los mecanismos fisiopatológicos que participan en el desarrollo de esta condición. Particularmente, la terapia celular con células madre neuronales y células madre mesenquimales ha demostrado, en estudios con animales y en estudios preclínicos con humanos, ser eficiente y segura para prevenir la hidrocefalia originada a partir de la disrupción de la zona ventricular y secundaria a la hemorragia intraventricular, con la consiguiente prevención de las secuelas neurológicas sensoriomotoras y cognitivas. Conclusiones: Hasta el momento no tenemos un tratamiento eficiente que ofrezca calidad de vida a los pacientes con hidrocefalia, y que esa alternativa terapéutica sea efectiva.
\end{abstract}

PALABRAS CLAVE: Hidrocefalia congénita. Hidrocefalia neonatal. Terapia celular. Hemorragia intraventricular. Derivación ventriculoperitoneal. Células madre.

\begin{abstract}
Introduction: Fetal hydrocephalus, perinatal and neonatal represents a major therapeutic challenge and often has with poor neurological prognosis, due to its heterogeneous aetiology, including neurodevelopmental disorders. Objective: To make a collection of advances in cell therapy as a proposal that can extend the spectrum of treatment in congenita-neonatal hydrocephalus. Development: Therapeutic interventions available at present as the ventricle-peritoneal shunt and third ventriculostomy, are insufficient to fully resolve the hydrocephalus and to prevent or reverse the associated neurological damage. This is why what has emerged the need for new therapeutic alternatives based on the knowledge of physiopathological mechanisms involved in the development of this condition. In particular, cell therapy with neural stem cells and mesenchymal stem cells has proven in animal studies and preclinical studies with humans, efficiently and safely to prevent hydrocephalus originated from the disruption of the ventricular zone and secondary to intraventricular hemorrhage, with the consequent
\end{abstract}

\footnotetext{
Correspondencia:

*Luis Rafael Moscote-Salazar

CIB, Fac. Medicina, Campus de Zaragocilla

Cartagena de Indias, Colombia

E-mail: mineurocirujano@aol.com;

rafaelmoscote21@gmail.com
}

Fecha de recepción: 29-05-2018

Fecha de aceptación: 05-06-2018

DOI: 10.24875/CIRU.18000054

Cir Cir. 2018;86:575-582

Contents available at PubMed

www.cirugiaycirujanos.com 
prevention of neurological sequelae sensorimotor and cognitive. Conclusions: So far, we do not have an efficient treatment that offers quality of life to patients with hydrocephalus, and that alternative therapy to be effective.

KEY WORDS: Congenital hydrocephalus. Hydrocephalus neonatal. Cell therapy. Intraventricular hemorrhage. Ventriculoperitoneal derivation. Stem cell.

\section{Introducción}

La hidrocefalia congénita y neonatal es una condición pediátrica de etiología heterogénea, cuyas causas incluyen la producción excesiva de líquido cefalorraquídeo (LCR) o la obstrucción de su circulación debido a alteraciones del neurodesarrollo'. Por otro lado, se encuentra la hidrocefalia secundaria a lesiones desencadenadas por hemorragia intracraneal, infecciones o tumores cerebrales, que más comúnmente se dan durante el periodo neonatal ${ }^{2}$.

Algunos estudios sugieren que hasta el $78 \%$ de los pacientes con hidrocefalia congénita 0 neonatal padecen déficits neurológicos residuales, con tasas de discapacidad que alcanzan hasta el $28 \%{ }^{3}$.

Actualmente existen tres opciones terapéuticas para la hidrocefalia fetal y neonatal: la derivación ventriculoperitoneal figura como primera opción, la cual está indicada en neonatos con un peso corporal mayor de $2000 \mathrm{~g}$, siendo el drenaje extraventricular intermitente la alternativa en pacientes con bajo peso corporal mientras alcanzan la meta para la intervención quirúrgica; como tercera opción se encuentra la tercera ventriculostomía endoscópica, cuya indicación está limitada a la hidrocefalia de tipo no comunicante y en pacientes mayores de 1 año $0^{1,4,5}$.

El $80-90 \%$ del deterioro neurológico sufrido por neonatos con hidrocefalia de inicio fetal dependientes de derivación no se revierte mediante la cirugía ${ }^{6}$. Es evidente que las terapias disponibles para la hidrocefalia de inicio fetal y neonatal son insuficientes para dar una real solución a esta condición y para mejorar el pronóstico neurológico de estos pacientes, y además representan altos costos para el sistema de salud en el escenario a largo plazo.

El propósito de esta revisión es exponer las investigaciones disponibles sobre estos tratamientos y los hallazgos que se han descrito.

\section{Fisiopatología de la hidrocefalia congénita-neonatal}

La hidrocefalia congénita y neonatal puede ser causada por anomalías genéticas primarias que desarrollan el daño de manera directa, o por mecanismos secundarios de lesión que se producen como resultado de la expansión de los ventrículos o la fisiología del LCR alterada. Estudios recientes sugieren que, además de malformaciones como Chiari II y Dandy-Walker, los mecanismos congénitos principales implican estenosis u obstrucción del acueducto de Silvio, denudación ependimaria y alteraciones en el órgano subcomisural (SCO) ${ }^{3}$.

En cuanto a los mecanismos de lesión secundarios, la hemorragia intraventricular (HIV) a partir de la hemorragia de la matriz germinal figura como la principal causa.

\section{Hidrocefalia a partir de una disrupción de la zona ventricular}

Existen dos zonas germinales, conocidas como zona ventricular (ZV) y zona subventricular (ZSV), que se encuentran asociadas con la pared ventricular y donde se producen todas las células del cerebro. La ZV está conformada por la neuroglia radial o células madre neuronales (NSC), que son células multipotentes diferenciadas a partir de las células neuroepiteliales que cubren el tubo neural hasta la semana 12 de gestación. La ZSV surge alrededor de la semana 14, cuando las NSC se dividen originando las células progenitoras neuronales (NPC), de cuya proliferación depende la formación de esta segunda zona germinal. A partir de las 18 semanas de gestación, aproximadamente, las NPC se diferencian en neuroblastos e inician la migración neuronal utilizando el proceso basal de las NSC como anclaje. A su vez, el proceso de ependimogénesis (diferenciación de las neuronas radiales/NSC en células ependimarias para recubrir las paredes ventriculares) comienza alrededor de las 18 semanas y se completa después del nacimiento, mientras que la gliogénesis comienza alrededor de las 15 semanas y continúa durante varios meses después del nacimiento ${ }^{7}$.

La interrupción de la ZV del acueducto de Silvio se asocia con la aparición de hidrocefalia ${ }^{8,9}$. Dicha alteración surge de un proceso común que incluye alteraciones en el tráfico de vesículas, uniones celulares 
anormales y pérdida de la integridad de la ZV. Este proceso se inicia alrededor de la semana 16 y finaliza durante la primera semana posnatal, afectando por igual a las NSC y las células ependimarias que forman la ZV en las etapas prenatal y posnatal del desarrollo, respectivamente ${ }^{10}$.

Hasta la semana 12 de gestación, en el tubo neural las células neuroepiteliales se diferencian en NSC para formar la ZV, estas uniones estrechas dejan de expresarse y la adhesión de células NSC viene dada solo por uniones gap y uniones adherentes (dependientes de calcio con N-cadherina) $)^{9,11}$.

Las causas de la hidrocefalia secundaria son: 1) la pérdida de la PTB, una proteína de unión de ARN expresada en las NSC, induce la falta de expresión gradual de las uniones adherentes en la ZV, con el inicio de la hidrocefalia12; 2) los animales con pérdida de las proteínas Numb y Numbl desarrollan hidrocefalia, y estas proteínas son necesarias para mantener las uniones adherentes en las NSC ${ }^{13}$; 3) el uso de anticuerpos contra $\mathrm{N}$-cadherina, la principal molécula implicada en las uniones adherentes, desencadena el desprendimiento de células ependimales de la pared dorsal del acueducto de Silvio ocasionando hidrocefalia ${ }^{14}$; y 4) en los ratones se desarrolla hidrocefalia con la mutación de un gen que codifica para $\alpha$ Snap, la cual es una proteína del tráfico intracelular cuya alteración da como resultado un transporte anormal de $\mathrm{N}$-cadherina a la membrana plasmática de las NSC, acumulándose en el citoplasma, con la consecuente disrupción masiva de la $\mathrm{ZV}^{10}$.

El latido ciliar es esencial para mantener un flujo de LCR laminar, ergo, la disrupción de la ZV con pérdida de algunas áreas del epéndimo-multiciliado afecta el trayecto del LCR a través del acueducto, contribuyendo al desarrollo progresivo de hidrocefalia, y la pérdida completa de epéndimo de la pared dorsal del acueducto conduce a la fusión de las paredes ventrales y dorsal denudadas, con la posterior estenosis y obliteración del acueducto cerebral, ocasionando la aparición de hidrocefalia ${ }^{10,11}$.

La disrupción de la ZV da como resultado dos eventos neuropatológicos significativos: la translocación de NSC/NPC al LCR, convirtiéndose en neuroesferas que muestran las mismas características de alteración de unión celular y pueden utilizarse para estudiar este fenómeno ${ }^{8,15}$, y la formación de heterotopía periventricular (HP) de materia gris subependimaria, que corresponde a la acumulación de neuroblastos como consecuencia del fracaso de estos en la migración por pérdida de la estructura de las NSC que les sirve como anclaje $^{10}$. En los fetos hidrocefálicos humanos estudiados, se ha encontrado HP en fetos de 21 y de 40 semanas ${ }^{11}$. La HP se comporta como focos epileptógenos y puede explicar la epilepsia que ocurre en pacientes con hidrocefalia congénita, afectando al 6-30\% de los casos $^{11,16}$.

Además de las anomalías en las uniones celulares y el transporte de vesículas, deben tenerse en cuenta otros mecanismos que ocasionan disrupción de la ZV, como infecciones o hemorragia intracerebral, y solo en una minoría de casos se asocia con herencia mendeliana, con hidrocefalia ligada a $\mathrm{X}$ como el tipo más común ${ }^{8}$.

\section{Hidrocefalia secundaria a hemorragia intraventricular}

La HIV ocurre como consecuencia de un sangrado de la matriz germinal (MG), la cual es una estructura localizada a lo largo del ventrículo lateral y altamente vascularizada. La patogenia de la HIV se ha asociado a: 1) alteración en el flujo sanguíneo cerebral; 2) fragilidad inherente de la vasculatura de la MG (dada por inmadurez de la barrera hematoencefalica (BHE), incluida la escasez de pericitos); y 3) trastornos de la coagulación ${ }^{6}$. Se ha sugerido que estas condiciones, asociadas a factores de riesgo clínico como el parto vaginal, puntaje bajo de Apgar, síndrome de dificultad respiratoria grave, neumotórax, hipoxia, hipercapnia, convulsiones e infección, pueden provocar importantes fluctuaciones en el flujo sanguíneo cerebral o en la presión sanguínea vascular, contribuyendo así a la rotura de la microvasculatura con la consiguiente hemorragia de la $M^{16,17}$. Posterior al sangrado de la MG con drenaje hacia los ventrículos cerebrales, la hemólisis de la sangre en el espacio intraventricular eleva la concentración de hemoglobina extracelular, la cual inicia respuestas inflamatorias, quimiotácticas y de apoptosis ${ }^{18}$. Este desequilibrio entre la producción y la reabsorción de LCR da como resultado el progreso de la hidrocefalia poshemorrágica ${ }^{19}$.

Más del $50 \%$ de los recién nacidos prematuros con HIV grave (grado >3) mueren o desarrollan hidrocefalia poshemorrágica (HPH), que requiere cirugía de derivación hasta en el $70 \%$ de los casos ${ }^{17}$. La HIV se asocia con daño cerebral importante, en especial en la sustancia blanca periventricular, que es exacerbado por la HPH y finalmente resulta en un aumento de la mortalidad y de la morbilidad neurológica a largo plazo, como convulsiones, parálisis cerebral y retraso del desarrollo en los sobrevivientes. 


\section{Terapias celulares disponibles para el tratamiento de la hidrocefalia}

Investigaciones recientes han establecido las bases para una terapia celular como alternativa terapéutica de la hidrocefalia fetal y neonatal. Las células potencialmente útiles para estos trasplantes o injertos son las NSC, las células madre mesenquimales (MSC), las células madre pluripotentes inducidas y las células de SCO. El resultado esperado con esta terapia es un microambiente adecuado para el nicho neurogénico embrionario, y en consecuencia un desarrollo cerebral normal ${ }^{6}$.

En modelos animales, las NSC/NPC, ya sean libres o formando neuroesferas, son fáciles de obtener y son las candidatas más confiables debido a su función de formar neuronas y glía, y por su bajo riesgo de tumorogénesis. A pesar de las limitaciones técnicas y éticas, se han obtenido NSC de embriones humanos y aloinjertos en modelos animales de pacientes con enfermedad de Parkinson ${ }^{20,21}$. Existe una variedad de células madre, como las células madre embrionarias humanas, las MSC o las células madre pluripotentes inducidas, que se encuentran bajo investigación para el tratamiento de la enfermedad de Parkinson y de otros trastornos cerebrales humanos 22,23 .

\section{Células madre neurales}

Teniendo en cuenta el mecanismo fisiopatológico de disrupción de la ZV ya descrito, se han realizado injertos de neuroesferas formadas por NSC o por NPC en los ventrículos laterales de ratas con hidrocefalia, para propósitos regenerativos. Después de 48 horas del trasplante, las células injertadas se integran selectivamente en las áreas de la ZV donde se produjo la denudación, y se cree que la capacidad de las NSC para migrar y diferenciarse en el tipo celular requerido depende de las áreas dañadas que liberan factores quimiotácticos específicos ${ }^{10}$. En la encefalomielitis autoinmunitaria de ratones, en la que las neuroesferas injertadas en el LCR originan NPC que ingresan a las áreas desmielinizadas, se diferencian en células cerebrales maduras y promueven la mielinización multifocal y la recuperación funcional ${ }^{24}$.

Existen al menos cinco ventajas de usar NSC: están disponibles en el cerebro embrionario y adulto, pueden ser trasplantadas, migran, tienen capacidad de diferenciación y se integran en áreas dañadas. Las NSC en la ZSV adulta tienen el potencial de ser una fuente autóloga de células de reemplazo. Cuando el cerebro se lesiona, las NSC se activan, proliferan y se diferencian en células recién nacidas, y la integración de estas células puede reemplazar las neuronas dañadas ${ }^{10}$. Sin embargo, este mecanismo de protección requiere ciertas condiciones y tiene un límite, por lo que ha sido necesario encontrar mecanismos que faciliten y potencien los beneficios de estos injertos.

Un estudio conducido por Yuan, et al. ${ }^{24}$ evaluó el efecto protector de la combinación de la movilización de NSC endógenas mediante el factor estimulante de colonias de granulocitos (G-CSF) y el tratamiento con cloruro de litio en la HPH. Este estudio se basó en varios conceptos clave: 1) el G-CSF estimula la proliferación, la supervivencia y la maduración de células comprometidas con el linaje de granulocitos a través de la unión al receptor específico de G-CSF; 2) el cloruro de litio es un agente neuroprotector que inhibe la apoptosis y la inflamación celular mediante la supresión de la actividad de la glucógeno sintasa cinasa $3 \beta$ y la mejora de la absorción de BrdU; y 3) el litio regula además la vía de señalización Wnt, la cual cumple una función clave en la proliferación y diferenciación de las NSC. Los resultados demostraron que el uso individual de G-CSF o de cloruro de litio solo alivió en parte la incidencia de HPH. Por el contrario, el tratamiento combinado de G-CSF y cloruro de litio atenuó significativamente $(p=0.015)$ el desarrollo de hidrocefalia después de la HIV en ratas. Los resultados mostraron además que la apoptosis neuronal se redujo significativamente por el tratamiento de combinación con G-CSF y cloruro de litio $(p=0.001)^{24}$.

Respecto al momento óptimo para el injerto de NSC, es preciso recordar que la disrupción de la ZV ocurre alrededor de las 16 semanas y continúa durante el segundo y el tercer trimestres de la gestación; parece entonces razonable sugerir que el injerto de NSC debe realizarse poco después de que se haya activado este proceso de denudación de la ZV. La cirugía fetal para reparar defectos del tubo neural, como mielomeningocele y espina bífida, se realiza entre las 19 y las 25 semanas según el estudio MOMS, siendo este el rango establecido por el tamaño y la fragilidad del feto antes de las 18 semanas y por el mayor riesgo de parto prematuro después de 30 semanas $^{25}$. Es importante tener en cuenta que estos pacientes tienen una disrupción de la ZV y la mayoría de los fetos que nacen con espina bífida tienen hidrocefalia ${ }^{10,25}$. El injerto de NSC en el cerebro hidrocefálico daría como resultado el reemplazo de 
células o la generación de un microambiente protector para evitar la interrupción progresiva de la ZV y para mejorar las respuestas gliales favorables ${ }^{25}$.

Todas estas investigaciones con NSC necesitan el aislamiento de estas células de origen humano, para lo cual se han logrado buenos avances con la obtención de una línea de NSC inmortale ${ }^{26}$ y una línea de NSC derivadas del estriado ${ }^{27}$.

\section{Células madre mesenquimales}

Estas células son particularmente atractivas para las terapias celulares, pues son células madre adultas versátiles y multipotentes, capaces de diferenciarse en diversos tipos de células, incluyendo NPC 6 . Si bien la médula ósea es la fuente mejor caracterizada de MSC, su uso es limitado por representar un proceso invasivo para su adquisición y el bajo número de MSC presentes $^{19}$. Existe gran disponibilidad de estas células en sangre de cordón umbilical, membranas placentarias y líquido amniótico, los cuales son tejidos gestacionales que generalmente se desechan en el ámbito hospitalario $\mathrm{y}$, por ende, no tienen limitaciones éticas ni de seguridad significativas ${ }^{19,28}$. Además, se ha demostrado que la mayor edad de los donantes se traduce en un impacto negativo en el potencial de expansión y diferenciación de las MSC, a diferencia de cuando se originan de tejidos gestacionales, que muestran menor inmunogenicidad, mayor capacidad de proliferación, mayor potencia paracrina y mayor eficacia terapéutica in vivo, en comparación con las MSC derivadas de tejido adulto como la médula ósea ${ }^{19}$.

La utilidad de las MSC en el tratamiento de la HPH fue demostrada en un estudio realizado en 2013 por Ahn, et al. ${ }^{29}$, quienes indujeron HIV grave (grado 3 o más) en ratas inyectándoles sangre en los ventrículos al cuarto día posnatal. Posteriormente se trasplantaron MSC derivadas de sangre de cordón umbilical o fibroblastos, vía intraventricular, en el sexto día posnatal. Los resultados fueron evaluados mediante pruebas seriales de resonancia magnética cerebral, pruebas de función conductual (como la prueba de geotaxis negativa y la prueba de rotarod) y análisis histológicos y bioquímicos en tejidos cerebrales y LCR obtenidos en el día 32 posnatal. Finalmente, el estudio demostró que el trasplante intraventricular de MSC derivadas de sangre de cordón umbilical humano, pero no los fibroblastos, fue efectivo 2 días después de la inducción de HIV grave, atenuando significativamente la hidrocefalia poshemorrágica, la función conductual alterada en las pruebas de geotaxis negativa y rotarod, las anomalías histológicas tales como la gliosis astrocítica aumentada y las células TUNEL y GFAP positivas, el aumento de citocinas inflamatorias (como IL-1a, IL-1ß, IL-6 y TNF- $\alpha$ ), la reducción del espesor del cuerpo calloso y la expresión de MBP. Los efectos protectores de las MSC podrían estar mediados por sus efectos paracrinos antiinflamatorios y antiapoptóticos, más que por sus capacidades regenerativas como en el caso de las NSC. Estos efectos pueden estar mediados por diversos factores de crecimiento y citocinas, como el factor de crecimiento endotelial vascular, el factor de crecimiento nervioso, el factor neurotrófico derivado del cerebro (BDNF), el factor neurotrófico derivado de la línea celular glial y la IL-10, que además estimulan la proliferación celular endógena y la diferenciación después de la HIV grave; al secretar estos factores tróficos, las MSC podrían promover el cambio de un entorno proinflamatorio a un ambiente antiinflamatorio o tolerante ${ }^{29}$.

Se ha evaluado el papel del BDNF como mediador del efecto neuroprotector de las MSC, y se ha concluido que este factor neurotrófico es clave en la función de dichas células para prevenir la HPH y atenuar el daño neurológico tras una HIV, pues estos efectos fueron eliminados al administrar por transferencia de ARN anticuerpos neutralizantes de BDNF in vitro en un cultivo de células neuronales de rata expuestas a trombina, y a su vez estos efectos neuroprotectores se restauraron mediante la administración de suplementos de factor neurotrofico derivado del cerebro (rhBDN) ${ }^{30}$.

\section{CoNSIDERACIONES DEL TRASPLANTE DE MSC: TIEMPO, VÍA DE ADMINISTRACIÓN Y DOSIS}

El momento oportuno para esta terapia celular es un tema clave, pues influye en la eficacia del tratamiento. Park, et al. ${ }^{31}$ realizaron un estudio para evaluar la ventana terapéutica del trasplante de MSC humanas derivadas de sangre de cordón umbilical después de una HIV grave, y encontraron que la eficacia neuroprotectora de las MSC dependió del tiempo, con una atenuación significativa de la HPH y de los marcadores de daño cerebral descritos anteriormente, solo cuando se administran temprano, a los 2 días de desarrollada la HIV grave, pero no con el injerto tardío a los 7 días.

Las rutas de administración ensayadas han sido por vía intraventricular ${ }^{29,32,33}$, intratecal ${ }^{34}$, intranasal ${ }^{35,36}$ y sistémica intraperitoneal o intravenosa ${ }^{32}$, concluyendo 
que a pesar de que tanto la administración local intraventricular e intratecal como la administración sistémica intravenosa son eficaces al atenuar significativamente la HPH y los criterios de daño cerebral después de una HIV grave, la vía intraventricular es preferible debido a que necesita una dosis cinco veces menor que la vía intravenosa, y aun así logra mayor cantidad de MSC en el sitio de lesión periventricular $^{33}$. Además, como la fontanela anterior está abierta en los recién nacidos, el trasplante local de MSC es factible en un entorno clínico a través de un canto ventricular, sin ninguna operación invasiva adicional ${ }^{19}$. La inyección de MSC en el ventrículo da lugar a la distribución de estas células alrededor de ambas zonas periventriculares, lo que indica la búsqueda exitosa de las MSC trasplantadas a sitios de inflamación o lesión ${ }^{29}$. No obstante, debido a que más de un 90\% de las HIV ocurren dentro de los 3 días posnatales, un periodo de mayor vulnerabilidad, algunos pacientes prematuros críticamente enfermos e inestables no tolerarán la administración intraventricular, por lo que se considera que la administración sistémica intravenosa puede ser una mejor alternativa en estos pacientes ${ }^{33}$. Sin embargo, dado que la desventaja en este escenario sería que las MSC trasplantadas sistémicamente se pueden retener en otros órganos, como los pulmones, el hígado, el bazo y los riñones ${ }^{19,33}$, existe otra ruta o vía de administración cuya investigación se encuentra en curso actualmente, y es la tecnología de encapsulación celular, la cual es trasplantada al LCR y podría superar el problema del rechazo de injertos. Esta estrategia implica el uso de células modificadas genéticamente que secretan proteínas con potencial terapéutico y están inmovilizadas dentro de una membrana polimérica semipermeable y preferiblemente de alginatos como el material más adecuado, debido a su abundancia y biocompatibilidad6.

Respecto a la dosis óptima, se ha observado que esta puede reducirse de 5×105 a 1×105 células si se elige la administración intraventricular local en vez de la administración intravenosa sistémica ${ }^{19,37}$.

\section{SEguRIDAD Y RESULTADOS A LARGO PLAZO DEL INJERTO DE MSC}

La seguridad del trasplante con MSC ha sido evaluada en estudios con animales, en los que se ha demostrado que su aplicación es segura a corto y largo plazo, sin presentarse en ninguno de ellos tumorogenicidad y persistiendo los efectos neuroprotectores a largo plazo en materia histológica, sensoriomotora y cognitiva ${ }^{19,36}$. Se evidenció incluso que menos del 1\% de las células injertadas se detectaron 18 días después de la administración intraventricular ${ }^{38}$.

La evidencia ha demostrado que la seguridad de las terapias con células madre dependerá de varios factores, como el estado de diferenciación y la capacidad proliferativa de las células injertadas, del momento y la vía de administración, y de la supervivencia a largo plazo del injerto ${ }^{10}$. Los datos evidenciados en estudios preclínicos que indican los efectos protectores mantenidos a largo plazo del trasplante de MSC, sin ningún efecto adverso, justifican la traducción del trasplante de MSC en estudios clínicos en humanos para el tratamiento de trastornos cerebrales neonatales ${ }^{37}$.

Al evaluar la seguridad y la viabilidad del trasplante intraventricular de MSC alogénico humano derivado de sangre de cordón umbilical humano en recién nacidos prematuros con HIV grave dentro de los 7 días posteriores a la detección de esta se encontró muerte no sospechada o shock anafiláctico dentro de las 6 horas posteriores al trasplante de MSC y muerte o hidrocefalia que requiere cirugía de derivación hasta 1 año ${ }^{39}$.

\section{Células madre del órgano subcomisural}

El SCO es una glándula secretora ependimal ubicada en la entrada del acueducto cerebral. Su principal función es secretar espondina al LCR y formar la fibra de Reissner, la cual se extiende a través del acueducto de Silvio, el cuarto ventrículo y el canal central de la médula espinal, siendo indispensable para mantener la permeabilidad del acueducto y el flujo normal de LCR. Un defecto congénito del SCO resulta en hidrocefalia ${ }^{6}$. Además de la espondina, el SCO secreta transtiretina y la proteína $S 100 \beta$, que apoyan el desarrollo embrionario del cerebro. Recientemente se ha encontrado evidencia para proponer que estos factores tienen funciones similares en la neurogénesis adulta, regulando la proliferación, la migración y la diferenciación de las NSC y de precursores neuronales en nichos neurogénicos adultos. Dichos hallazgos proporcionan una base para motivar la investigación de una terapia basada en células del SCO. 


\section{Células madre pluripotentes inducidas}

Actualmente es posible reprogramar los fibroblastos de la piel adulta en células madre pluripotentes inducidas. Esta modalidad se ha ensayado para cultivar tejido neural tridimensional a partir de células madre pluripotentes humanas y tratar la microcefalia ${ }^{40}$. Los organoides cerebrales resultantes alcanzaron hasta $4 \mathrm{~mm}$ de tamaño y contenían células madre radiales polarizadas que rodean una cavidad llena de líquido que se asemeja al ventrículo lateral en el cerebro en desarrollo. Este modelo puede servir como una valiosa plataforma in vitro para estudiar los mecanismos moleculares que regulan el desarrollo de la corteza cerebral, y podría proporcionar un enfoque innovador y complementario para el estudio de la disrupción de la ZV que conduce a hidrocefalia y neuro/gliogénesis anormal in vitro.

\section{Conclusiones}

La terapia celular ha surgido como una prometedora alternativa terapéutica y su importancia va más allá de controlar la hidrocefalia, centrándose en la mejoría o incluso en la prevención de las secuelas neurológicas que hasta el momento se consideran irreversibles. Se ha demostrado la eficacia del trasplante de NSC y MSC para prevenir la hidrocefalia congénita por disrupción de la ZV y la hidrocefalia neonatal poshemorrágica, respectivamente. Sus ventajas incluyen una intervención única en la vida, lo que disminuiría las complicaciones derivadas de subsiguientes intervenciones y los costos a largo plazo; han demostrado utilidad para prevenir y revertir el daño neurológico, lo que representa una menor carga de morbilidad en los pacientes con hidrocefalia; son fáciles de obtener, sobre todo las MSC; y no acarrean limitaciones éticas significativas.

Algunas desventajas son que, si bien el mejor momento para el injerto celular de NSC es en la semana 16 , resulta difícil predecir o diagnosticar en esa etapa de la gestación que el paciente desarrollará hidrocefalia. Aunque se ha demostrado que la mayoría de los pacientes con espina bífida presentan a su vez hidrocefalia, no existen estudios que demuestren esta asociación y que permitan asumir que todo paciente con un defecto del tubo neural desarrollará hidrocefalia, justificando el trasplante. La sangre de cordón umbilical es heterogénea y varía mucho el número de células de un espécimen a otro, lo que dificulta la protocolización de la dosis.
Hasta el momento no tenemos un tratamiento eficiente que ofrezca calidad de vida a los pacientes con hidrocefalia, y esa alternativa terapéutica que necesitamos surgirá a partir de una mejor comprensión de los mecanismos biológicos de las anomalías cerebrales que precipitan la hidrocefalia congénita y neonatal.

\section{Conflicto de intereses}

Ninguno de los autores o familiares directos tiene conflicto de intereses que puedan influenciar el contenido de este manuscrito.

\section{Financiación}

Este trabajo no recibió ningún tipo de financiación.

\section{Bibliografía}

1. Oi S, Inagaki T, Shinoda M, Takahashi S, Ono S, Date I, et al. Guideline for management and treatment of fetal and congenital hydrocephalus: Center of Excellence - Fetal and Congenital Hydrocephalus Top 10 Japan Guideline 2011. Child's Nerv Syst. 2011;27:1563-70.

2. Yamasaki M, Nonaka M, Bamba $Y$, Teramoto $C$, Ban C, Pooh RK. Diagnosis, treatment, and long-term outcomes of fetal hydrocephalus. Semin Fetal Neonatal Med. 2012;17:330-5.

3. McAllister JP. Pathophysiology of congenital and neonatal hydrocephalus. Semin Fetal Neonatal Med. 2012;17:285-94.

4. Rekate HL. Selecting patients for endoscopic third ventriculostomy. Neurosurg Clin N Am. 2004;15:39-49.

5. Nishiyama K, Mori H, Tanaka R. Changes in cerebrospinal fluid hydrodynamics following endoscopic third ventriculostomy for shunt-dependent noncommunicating hydrocephalus. J Neurosurg. 2003;98:1027-31.

6. Guerra M, Blázquez JL, Rodríguez EM. Blood-brain barrier and foetal-onset hydrocephalus, with a view on potential novel treatments beyond managing CSF flow. Fluids Barriers CNS. 2017;14:19.

7. Browd SR, Ragel BT, Gottfried ON, Kestle JRW. Failure of cerebrospinal fluid shunts: part I: obstruction and mechanical failure. Pediatr Neurol. 2006;34:83-92.

8. Domínguez-Pinos MD, Páez $P$, Jiménez A-J, Weil B, Arráez M-A, Pérez-Fígares J-M, et al. Ependymal denudation and alterations of the subventricular zone occur in human fetuses with a moderate communicating hydrocephalus. J Neuropathol Exp Neurol. 2005;64:595-604.

9. Wagner C, Batiz LF, Rodríguez S, Jiménez AJ, Páez P, Tomé M, et al. Cellular mechanisms involved in the stenosis and obliteration of the cerebral aqueduct of hyh mutant mice developing congenital hydrocephalus. J Neuropathol Exp Neurol. 2003;62:1019-40.

10. Rodríguez EM, Guerra MM. Neural stem cells and fetal-onset hydrocephalus. Pediatr Neurosurg. 2017;52:446-61.

11. Guerra MM, Henzi R, Ortloff A, Lichtin N, Vío K, Jiménez AJ, et al. Cell junction pathology of neural stem cells is associated with ventricular zone disruption, hydrocephalus, and abnormal neurogenesis. J Neuropathol Exp Neurol. 2015;74:653-71.

12. Shibasaki T, Tokunaga A, Sakamoto R, Sagara H, Noguchi S, Sasaoka T, et al. PTB deficiency causes the loss of adherens junctions in the dorsal telencephalon and leads to lethal hydrocephalus. Cereb Cortex. 2013;23:1824-35

13. Rašin M-R, Gazula V-R, Breunig JJ, Kwan KY, Johnson MB, Liu-Chen S, et al. Numb and Numbl are required for maintenance of cadherin-based adhesion and polarity of neural progenitors. Nat Neurosci. 2007; 10:819-27.

14. Oliver C, González CA, Alvial G, Flores CA, Rodríguez EM, Bátiz LF. Disruption of $\mathrm{CDH} / \mathrm{N}$-cadherin-based adherens junctions leads to apoptosis of ependymal cells and denudation of brain ventricular walls. J Neuropathol Exp Neurol. 2013;72:846-60.

15. Guerra M, Sival D, Jiménez A, Domínguez Pinos $M$, den Dunnen W Bátiz L, et al. Defects in cell-cell junctions lead to neuroepithelial/ependymal denudation in the telencephalon of human hydrocephalic foetuses. Cerebrospinal Fluid Res. 2010;7(Suppl 1):S56

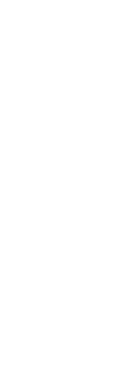


16. Ballabh $P$. Intraventricular hemorrhage in premature infants: mechanism of disease. Pediatr Res. 2010;67:1-8.

17. Ahn SY, Chang YS, Park WS. Mesenchymal stem cells transplantation for neuroprotection in preterm infants with severe intraventricular hemorrhage. Korean J Pediatr. 2014:57:251.

18. Fang H, Wang P-F, Zhou Y, Wang Y-C, Yang Q-W. Toll-like receptor 4 signaling in intracerebral hemorrhage-induced inflammation and injury. J Neuroinflammation. 2013;10:794.

19. Park WS, Ahn SY, Sung SI, Ahn J-Y, Chang YS. Mesenchymal stem cells: the magic cure for intraventricular hemorrhage? Cell Transplant. 2017;26:439-48.

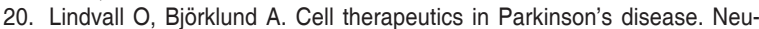
rotherapeutics. 2011;8:539-48.

21. Politis M, Lindvall O. Clinical application of stem cell therapy in Parkinson's disease. BMC Med. 2012;10:1

22. Lindvall O, Kokaia Z. Stem cells for the treatment of neurological disorders. Nature. 2006;441:1094-6.

23. Bjorklund A, Kordower JH. Cell therapy for Parkinson's disease: what next? Mov Disord. 2013;28:110-5.

24. Yuan Q, Bu X-Y, Yan Z-Y, Liu X-Z, Wei Z-Y, Ma C-X, et al. Combination of endogenous neural stem cell mobilization and lithium chloride treatment for hydrocephalus following intraventricular hemorrhage. Exp Ther Med. 2016;12:3275-81.

25. Guerra M. Neural stem cells: are they the hope of a better life for patients with fetal-onset hydrocephalus? Fluids Barriers CNS. 2014;11:7.

26. Cacci E, Villa A, Parmar M, Cavallaro M, Mandahl N, Lindvall O, et al Generation of human cortical neurons from a new immortal fetal neural stem cell line. Exp Cell Res. 2007;313:588-601.

27. Monni E, Cusulin C, Cavallaro M, Lindvall O, Kokaia Z. Human feta striatum-derived neural stem (NS) cells differentiate to mature neurons in vitro and in vivo. Curr Stem Cell Res Ther. 2014;9:338-46.

28. Castro-Manrreza ME, Montesinos JJ. Immunoregulation by mesenchymal stem cells: biological aspects and clinical applications. J Immuno Res. 2015;2015:394917.

29. Ahn SY, Chang YS, Sung DK, Sung SI, Yoo HS, Lee JH, et al. Mesenchymal stem cells prevent hydrocephalus after severe intraventricular hemorrhage. Stroke. 2013;44:497-504.
30. Ahn SY, Chang YS, Sung DK, Sung SI, Ahn J-Y, Park WS. Pivotal role of brain-derived neurotrophic factor secreted by mesenchymal stem cells in severe intraventricular hemorrhage in newborn rats. Cell Transplant. 2017;26:145-56.

31. Park WS, Sung SI, Ahn SY, Sung DK, Im GH, Yoo HS, et al. Optimal timing of mesenchymal stem cell therapy for neonatal intraventricular hemorrhage. Cell Transplant. 2016;25:1131-44.

32. Kim ES, Ahn SY, Im GH, Sung DK, Park YR, Choi SH, et al. Human umbilical cord blood-derived mesenchymal stem cell transplantation attenuates severe brain injury by permanent middle cerebral artery occlusion in newborn rats. Pediatr Res. 2012;72:277-84.

33. Ahn SY, Chang YS, Sung DK, Sung SI, Yoo HS, Im GH, et al. Optimal route for mesenchymal stem cells transplantation after severe intraventricular hemorrhage in newborn rats. PLoS One. 2015;10:e0132919.

34. Fang B, Wang H, Sun X-J, Li X-Q, Ai C-Y, Tan W-F, et al. Intrathecal transplantation of bone marrow stromal cells attenuates blood-spinal cord barrier disruption induced by spinal cord ischemia-reperfusion injury in rabbits. J Vasc Surg. 2013;58:1043-52.

35. Donega V, Nijboer $\mathrm{CH}$, van Velthoven CTJ, Youssef SA, de Bruin A, van Bel $\mathrm{F}$, et al. Assessment of long-term safety and efficacy of intranasal mesenchymal stem cell treatment for neonatal brain injury in the mouse. Pediatr Res. 2015;78:520-6.

36. Donega V, van Velthoven CTJ, Nijboer $\mathrm{CH}$, van Bel F, Kas MJH, Kavelaars $A$, et al. Intranasal mesenchymal stem cell treatment for neonatal brain damage: long-term cognitive and sensorimotor improvement. PLoS One. 2013;8:e51253.

37. Ahn SY, Chang YS, Park WS. Stem cells for neonatal brain disorders. Neonatology. 2016;109:377-83.

38. van Velthoven CTJ, Kavelaars A, van Bel F, Heijnen CJ. Mesenchymal stem cell transplantation changes the gene expression profile of the neonatal ischemic brain. Brain Behav Immun. 2011;25:1342-8.

39. Chang YS, Ahn SY, Sung S, Park WS. Stem cell therapy for neonatal disorders: prospects and challenges. Yonsei Med J. 2017;58:266-71.

40. Lancaster MA, Renner M, Martin C-A, Wenzel D, Bicknell LS, Hurles ME, et al. Cerebral organoids model human brain development and microcephaly. Nature. 2013;501:373-9. 